\title{
TOLL-LIKE RECEPTORS 4 AND 9 EXPRESSION IN SYSTEMIC LUPUS ERYTHEMATOSUS AND \\ DERMATOMYOSITIS: RELATION TO CLINICAL STATUS AND DISEASE ACTIVITY
}

\author{
E. A. Baraka ${ }^{1}$, Inas A. Ahmed ${ }^{2,3}$ \\ ${ }^{1}$ DEPARTMENT OF RHEUMATOLOGY \& REHABILITATION AND \\ PHYSICAL MEDICINE, FACULTY OF MEDICINE, BENHA \\ UNIVERSITY, EGYPT. \\ ${ }^{2}$ DEPARTMENT OF MEDICAL BIOCHEMISTRY, FACULTY OF \\ MEDICINE, BENHA UNIVERSITY, EGYPT. \\ ${ }^{3}$ MOLECULAR BIOLOGY AND BIOTECHNOLOGY UNIT, FACULTY \\ OF MEDICINE, BENHA UNIVERSITY, EGYPT
}

Received 26/10/2015 - Accepted 3/11/2015

\begin{abstract}
Systemic Lupus Erythematosus (SLE) is an autoimmune disorder affecting almost all organs and tissues. Dermatomyositis (DM) is a chronic muscle disorder that leads to muscle destruction. Although DM mechanisms remain unclear, there is an evidence of autoimmune origin. Toll-like receptors (TLRs) are the key initiators of innate and adaptive immune response due to high production of proinflammatory mediators and activation of antigen presentation. We used qPCR to investigate the expression of TLR4 and TLR9 in peripheral blood mononuclear cells (PBMCs) from SLE and DM patients, as well as muscle tissue biopsies from the DM patients, to explore their role and study their correlations with clinical manifestations and disease activity. Our findings showed a significant increase in TLR4 and TLR9 expression levels in PBMCs from SLE patients and muscle biopsies from DM patients. Such results emphasize the role of TLR signaling and innate immune system in the pathogenesis of both diseases.
\end{abstract}

\section{Keywords:}

Gene Expression, qPCR, Innate Immunity and Autoimmune Diseases.

68

* Correspondence Author (e mail: inas.ahmed@fmed.bu.edu.eg) 


\section{INTRODUCTION}

SLE is an autoimmune disorder of multifactorial origin, in genetically predisposed subjects, environmental factors, such as viral infections and smoking, induce the breakdown of self-tolerance eventually triggering autoimmune response (Tsokos, 2011). It is characterized by spontaneous lympho-proliferation, aberrant activation of $\mathrm{T}$ and $\mathrm{B}$ cells and production of auto-antibodies against nuclear DNA and / or other nuclear proteins (Mu et al., 2012).

$\mathrm{DM}$ is a chronic muscle disorder, clinically characterized by features of symmetric proximal muscle weakness. DM is a microangiopathy affecting the skin and muscle, in which the early activation and deposition of complement causes the lysis of endomysial capillaries and muscle ischemia. Perimysial and perivascular inflammation with $\mathrm{CD} 4+\mathrm{T}$ cell, B cells, and macrophage infiltrations are the histological features of DM (Kim et al., 2010).

TLRs is one of a group known as pattern recognition receptors that play a critical role in protective immunity against invading microorganisms. Pathogens, especially bacteria, have molecular structures that are not shared with their host and are relatively invariant named as Pathogen Associated Molecular Pattern (PAMPs) that are recognized by those TLRs such as bacterial DNA, flagellin, viral double stranded RNA (Pradhan et al., 2012).

At least 12 mammalian TLR family members have been identified, TLR1, $-2,-4,-5$ and -6 are on the cell surface and they interact with components found on the surface of pathogens whereas TLR3 and $7,-8$ and -9 - are expressed within intracellular vesicles and their ligands must be taken up into the endosome to result in activation (Blasius and Beutler, 2010).

Intracellular TLRs, apart from being able to recognize PAMPs they are also capable of recognizing endogenous ligands which are named Danger Associated Molecular Patterns (DAMPs) (Denk et al., 2012). In SLE patients, impaired apoptosis and invalid cell debris clearance lead to increased concentration of serum nucleic acids (ssRNA, dsRNA, and DNA), which are well-known ligands for TLR so Immune response is induced by not only microbial infection, but also by sterile tissue damage and degeneration product (Ma et al., 2015).

TLR activation leads to expression of genes such as inflammatory cytokines and co-stimulatory molecules. Eventually, antigen-specific 
acquired immunity is developed as a result of TLR-dependent gene expression pattern together with phagocytosis-mediated antigen presentation (Husebye et al., 2006). Yet, the exact roles of TLRs in the adaptive immune response are less well understood, offering an important area of future study (Iwasaki and Medzhitov, 2010).

This study was carried out to investigate the expression TLRs 4 and 9 in the peripheral blood mononuclear cells (PBMCs) of patients with SLE and DM as well as muscle tissue specimens from patients with DM and study their correlations with clinical manifestations and disease activity of both diseases.

\section{MATERIALS \& METHODS}

After approval of the study scheme by the ethical committee of Faculty of Medicine, Benha University, and obtaining an informed consent from participants, 32 SLE patients and 17 DM patients were enrolled into the current study. These patients were selected during regular follow-up at the outpatients' clinic and the inpatients' unit of the Rheumatology and Rehabilitation Department, Benha University Hospitals between November 2013 and March 2014 according to the SLICC and Bohan and Peter classification criteria for SLE and DM, respectively. Twenty age and sex matched apparently healthy volunteers were recruited as a control group.

All patients were subjected to full history taking, complete clinical examination. Disease activity was evaluated according to the Systemic Lupus Erythematosus Disease A ctivity Index (SLEDAI) score (Bombardier et al., 1992), assessment of SLE-related disease damage was done according to the Systemic Lupus International Collaborating Clinic (SLICC) damage index (Gladman et al., 1992). In patients with DM, assessment of disease activity was done according to DM disease activity score (DAS) (Bode et al., 2003). A muscle biopsy was taken from vastus lateralis muscle for the detection of TLR4 and TLR 9 from all DM patients as well as 10 of the control subjects who accepted the procedure with a "semi-open" muscle biopsy technique under local anesthesia.

Peripheral blood samples were withdrawn from all subjects and processed properly for routine investigations and separation of PBMCs using FICOLL-PAQUETM PLUS density-gradient medium (GE Healthcare, USA) according to the manufacturer's instructions (Bøyum, 1968). 
RNA isolation and quantitative RT PCR: All PBMCs samples and muscle specimens were immediately used for total RNA extraction using RNeasy mini kit (QIAgen, Germany) as previously described (Salway et al., 2008). RevertAid First Strand cDNA Synthesis Kit (Thermo Fisher Scientific, USA) was used, according to the manufacturer's instructions, for total RNA extraction (Wiame et al., 2000) and cDNA aliquots were stored at $-80^{\circ} \mathrm{C}$ till further processing. $T L R 4$ and TLR 9 gene expression assay of each sample was performed in duplicates using Maxima SYBR Green/ROX qPCR Master Mix (Thermoscientific / Fermentas, USA) by StepOne ${ }^{\text {TM }}$ Real-Time PCR System (Life Technologies, USA). Detection and quantification of each gene was expressed as relative mRNA level compared with a standard housekeeping gene (GAPDH) according to the $2^{-\Delta \Delta \mathrm{Ct}}$ method (Livak \& Schmittgen, 2001). The primers sequences are as follows: TLR4 Forward: 5'-CTTATAAGT GTCTGAACTCCC-3', Reverse: 5' -TACCAGCACGACTGCTCAG-3', GAPDH Forward: 5'CACCACCATGGAGAAGGCTG-3', Reverse: 5'GTGATGGCATGG ACTGTG-3' (Szebeni etal., 2008) and TLR9: Forward 5'-TGGTGTTGAAGGACAGTTCTCTC-3' and Reverse: 5'CACTCG GAG GTT TCCCAGC-3' (Mortaz et al., 2010).

Statistical analysis: Analysis of data was performed using SPSS (version 16, Statistical Program for Social Science). Comparisons were performed by the Chi-square test for qualitative variables. Mann Whitney and Student's t-test were used for quantitative variable and Spearman's correlation coefficients $(r)$ were calculated for detection of nonparametric correlations between variables in one group.

\section{RESULTS}

This study included 32 SLE patients, 28 females (87.5\%) and 4 males (12.5\%) $(\mathbf{F} / \mathbf{M}=\mathbf{7 / 1})$. Their ages ranged between17-45 years with a mean of $(\mathbf{3 0 . 1} \mathbf{\pm 9 . 4 )}$ years and disease duration from 9 months to 19 years with a mean of $3.44 \pm 4.01$ years. Clinical and laboratory characters are shown in tables $(1 \& 2)$.

The current study included $17 \mathrm{DM}$ patients as well (15 females, 88\% and 2 males 12\%) $(\mathbf{F} / \mathbf{M}=\mathbf{7 . 5 / 1})$. Their ages ranged between 9 and 52 years with a mean of $(\mathbf{2 2 . 6} \mathbf{\pm 1 5 . 2})$ years and disease duration ranging from 18 months to 15 years with a mean of $3.74 \pm 3.01$ years.

DM patients presented with various clinical features, all patients (100\%) had heliotrope rash and /or gottron sign and papules, 14 
patients $(82 \%)$ had Constitutional symptoms in the form of fever, malaise, weight loss , 12 patients $(71 \%)$ had calcinosis, $10(59 \%)$ had arthritis, 4 patients $(23.5 \%)$ had muscle power grade 3 and $14(82 \%)$ had muscle power grade 4 of the shoulder and /or pelvic girdle muscles. The control group included twenty subjects (14 females, $70 \%)$ and 6 males, $30 \%)(\mathbf{F} / \mathbf{M}=\mathbf{7 / 3})$. Their ages ranged between 1054 years with a mean of $\mathbf{( 3 1 . 3} \pm \mathbf{1 3 . 3})$ years.

The data retrieved from our study revealed that the expression levels of TLR 4 and TLR9 were significantly higher in the PBMCs from SLE patients compared to that of the controls $(\mathrm{P}<0.05)$. Table $(3)$

In addition, TLR4 expression levels in the PBMCs of SLE were significantly higher in those patients who had malar rash $(\mathrm{P}<0.05)$, alopecia $(\mathrm{P}<0.05)$, arthritis $(\mathrm{P}<0.05)$ and pericarditis $(\mathrm{P}<0.05)$. On the other hand, TLR4 mRNA expression showed a significant negative correlation with corticosteroid doses $(\mathrm{r}=-0.54, \mathrm{P}<0.05)$. Regarding TLR9 expression levels, they were higher in SLE patients with nephritis $(\mathrm{P}<0.05)$ and positively correlated with the protein /creatinine ratios $(\boldsymbol{r}=0.47, \mathrm{P}<0.05)$, the SLICC damage indices $(\boldsymbol{r}=0.59, \mathrm{P}<0.05)$ and negatively correlated with $\mathrm{C} 3$ levels $(\boldsymbol{r}=-0.53$, $\mathrm{P}<0.05)$.

In DM, TLR4 and TLR9 expression levels in the PBMCs showed insignificant difference between the patients and the control subjects $(\mathrm{P}>0.05)$ for both genes. However, their expression levels in the muscle biopsies from DM patient group were significantly higher $(\mathrm{P}<0.05)$ than in the muscle tissue from the control Table (4). Comparing the muscle biopsies to the PBMCs in DM patients showed significant higher TLR4 and TLR9 expression levels (both $\mathrm{P}<0.05$ ).

In the muscle biopsies from DM patients, both TLR4 and TLR9 expression levels, positively correlated with disease activity scores (DAS) $(\mathrm{P}<0.05)$ as well as with creatine kinase (IU/L) levels $(\mathrm{P}<0.05$, respectively). Furthermore, our results indicated that TLR 9 expression levels were significantly higher in patients who had calcinosis $(\mathrm{P}<0.05)$. However, only TLR4 expression levels exhibited a significant negative comelation with corticosteroid doses $(\mathrm{P}<0.05)$. 
Table (1): Clinical characteristics of SLE patients

\begin{tabular}{|c|c|c|c|}
\hline & \multicolumn{2}{|l|}{ No. $=32$} & Percentage $(\%)$ \\
\hline Fever & \multicolumn{2}{|l|}{18} & $\overline{56}$ \\
\hline Malar rash & \multicolumn{2}{|l|}{26} & 81 \\
\hline Alopecia & \multicolumn{2}{|l|}{15} & 47 \\
\hline Oral ulcer & \multicolumn{2}{|l|}{31} & 97 \\
\hline Arthritis & \multicolumn{2}{|l|}{29} & 91 \\
\hline Nephritis & \multicolumn{2}{|l|}{16} & 50 \\
\hline Respiratory & \multicolumn{2}{|l|}{13} & 41 \\
\hline Cardiac & \multicolumn{2}{|l|}{8} & 25 \\
\hline Neuropsychiatric & \multicolumn{2}{|l|}{3} & 9 \\
\hline \multirow{2}{*}{ SLEDAI score } & Active disease & 21 & 66 \\
\hline & Inactive disease & 11 & 34 \\
\hline \multirow{2}{*}{$\begin{array}{c}\text { SLICC } \\
\text { damage index }\end{array}$} & 0 & 21 & 66 \\
\hline & 1 & 11 & 34 \\
\hline
\end{tabular}

No.: total number, SLEDAI =the Systemic Lupus Erythematosus Disease Activity Index, SLICC= Systemic Lupus International Collaborating Clinic.

Table (2): Laboratory characteristics of SLE patients

\begin{tabular}{|c|cc|c|}
\hline \multirow{2}{*}{ C3 (mg/dl) } & \multicolumn{2}{|c|}{ No.=32 } & Percentage (\%) \\
\hline \hline \multirow{2}{*}{ C4 (mg/dl) } & Low & 13 & 41 \\
\cline { 2 - 4 } & Normal & 19 & 59 \\
\cline { 2 - 4 } ANA & Low & 13 & 41 \\
\hline Titre & Pormal & 19 & 59 \\
\cline { 2 - 4 } & Negative & 32 & 100 \\
\hline \multirow{2}{*}{$\begin{array}{c}\text { Anti ds- DNA } \\
\text { (U/ml) }\end{array}$} & Positive & 16 & 0 \\
\cline { 2 - 4 } & Negative & 16 & 50 \\
\hline \hline \multirow{2}{*}{$\begin{array}{c}\text { ESR } \\
\text { (mm/1st hour }\end{array}$} & 71.25 & Mean & 31.49 \\
\hline Hb (gm/dl) & 10.30 & 1.54 \\
\hline WBCS (thousands/ml) & 5.08 & 2.44 \\
\hline Platelets (thousands/ml) & 282.50 & 104.71 \\
\hline
\end{tabular}

$\mathbf{C 3}=$ complement $3, \mathbf{C 4}=$ complement $4, \mathbf{A N A}=$ anti- nuclear antibodies, Anti ds -DNA= anti double stranded deoxy nucleic acid. 
Table (3): TLR4 and TLR9 gene expression in PBMCs from SLE patients as compared to control subjects

\begin{tabular}{|c|c|c|}
\hline & SLE & Control \\
\hline \hline $\begin{array}{c}\text { TLR4 } \\
(\mathbf{R U )}) \\
\text { Mean } \pm \text { SD }\end{array}$ & $* 93.8 \pm 74.6$ & $46 \pm 11.3$ \\
\hline $\begin{array}{c}\text { TLR9 } \\
(\mathbf{R U}) \\
\text { Mean } \pm \text { SD }\end{array}$ & $* 87.9 \pm 74.9$ & $8.5 \pm 5.7$ \\
\hline
\end{tabular}

RU: Relative Units, * $\mathrm{P}<0.05$ significant

Table (4): TLR4 and TLR9 gene expression in PBMCs and muscle biopsies from DM patients as compared to control subjects

\begin{tabular}{|c|c||c|}
\hline & DM & Control \\
\hline \hline $\begin{array}{c}\text { PBMCs TLR4 } \\
\text { (RU) Mean } \pm \text { S.D }\end{array}$ & $42.1 \pm 11.9$ & $46 \pm 11.3$ \\
\hline $\begin{array}{c}\text { PBMCs TLR9 } \\
\text { RU) Mean } \pm \text { S.D }\end{array}$ & $6.9 \pm 2.2$ & $8.5 \pm 5.7$ \\
\hline Muscle TLR4 & $* 52.4 \pm 11.7$ & $6.9 \pm 2.3$ \\
\hline Muscle TLR9 & $* 8.3 \pm 2.3$ & $0.6 \pm 0.5$ \\
\hline
\end{tabular}

RU: Relative Units, * $\mathrm{P} \leq 0.05$ significant

\section{DISCUSSION}

Autoreactive B cells, present in the lymphoid tissue of healthy individuals remain silent due to presence of self-tolerance mechanisms. Upon failure of self-antigen tolerance, the antigen receptors co-engage with self-reactive antibodies, leading to activation of these autoreactive B cells and development of autoimmune diseases. TLRs that have been triggered by self-antigens, are suggested to respond to signals received by innate immune system, by induction of the secretion of inflammatory cytokines, thereby engaging lymphocytes to support an adaptive, antigen-specific immune response (Pradhan etal., 2012) (Lim \& Staudt, 2013). 
Our findings revealed significantly higher mRNA expression regarding TLR4 and TLR9 in PBMCs from SLE patients as compared to that of control subjects.

As far as we know, this is the first study to assess TLR 4 expression in PBMCs from SLE patients using qRT-PCR. The present results denote that it was upregulated in the patient group as compared to the control group. In spite of the lack of previous studies using the same technique, this finding supports the previous results showing that the protein expression of many TLRs including TLR4 and 9 in PBMCs of SLE patients compared to control subjects (Wong et al., 2010). However, this was inconsistent with flow cytometry results of the study by Migita et al. (2007). This controversy might be attributed not only to the different techniques, but also to different cell subpopulation as well as different patients' characteristics.

Furthermore, the significantly increased TLR9 expression in SLE group is in agreement with former studies using qRT-PCR (Komatsuda et al., 2008) (Mu et al. , 2012), and more recently using flow cytometry (Klonowska-Szymczyk et al., 2014).

In our SLE patients, TLR4 expression was significantly higher in those with malar rash, alopecia, arthritis and cardiac manifestations (all $\mathrm{P}<0.05)$. While, TLR9 expression was significantly higher in patients with nephritis, positively correlated with protein/creatinine ratios, and mean SLICC damage indices $(\mathrm{P}<0.05)$.

Previous experimental studies highlighted the role of TLR4 in the pathogenesis of SLE. It has been shown that overexpressing TLR4 alone mice is sufficient to induce lupus-like autoimmune disease. (Liu et al., 2006) Moreover, TLR4 deficient mice showed significant decrease of autoantibodies rates. Interestingly, $T L R 4$ has been reported to synergize with $T L R 7 \& 9$ ligands. Upon activation, TLR4, 9 transmit the signals through different adaptor molecules to activate dendritic cells (DCs), increase circulating cytokines levels specially IFN-I and finally enhance the disease (Crampton et al., 2014).

The present results regarding higher mRNA expression of TLR4 in SLE patients with malar rash, alopecia, arthritis and cardiac manifestations, could be attributed to the increased level of interferon type I (IFN-I) due to the continuous activation of TLR pathways by nucleic acids containing immunologic complexes (Elkon and Stone, 2011). IFN-alpha in turn, induces many interferon- inducible genes 
and its level correlates with SLE activity and more detrimental clinical disease forms (Rönnblom and Eloranta, 2013).

The role of TLR4 and TLR9 activation in pathogenesis of arthritis might be explained by their importance in differentiation of DCs into T-helper1 (Th1) cells (Abdollahi-Roodsaz et al., 2008) (Davila \& Kolls, 2010). In a mouse model of arthritis, aberrant TLR4 expression has been shown to disrupt the balance of Th1 and Th2 lymphocytes (Wong et al., 2010); an imbalance that is thought to be of pathogenic significance in rheumatoid arthritis (Dolhain et al., 1996). Moreover, TLR4 deficiency in mice models confers protection against the inflammatory process of rheumatoid arthritis due to the lowered capacity to produce interleukin-17 (Wong et al., 2010).

Interestingly, animal studies of SLE have implicated TLR9 as a receptor for hypomethylated DNA. SLE patients have higher level of nuclear debris with hypomethylated CpG-DNA that may serve as autoantigens to trigger TLR9 expression and exacerbate the inflammatory process through increased inflammatory cytokines levels including IFN-I (Yasuda et al., 2009) (Christensen et al., 2006).

Our results showed that TLR9 relative expression was significantly higher in SLE patients with positive anti-dsDNA antibodies $(\boldsymbol{P}<\mathbf{0 . 0 5})$. This is consistent with reports detecting a positive correlation between increased expression of TLR $9 \mathrm{mRNA}$ and the presence of anti-ds DNA antibody (Mu et al., 2012).

One possible mechanism is that autoantigens can bind B cell receptors and trigger TLR 9 expression, which results in B cell activation, proliferation, production and class-switching of autoantibody (Leadbetter et al., 2002) (Lin et al., 2004). This suggestion was ascertained by another study which showed that the production of anti-dsDNA antibodies was inhibited in TLR9-deficient lupus-prone mice (Christensen et al., 2006).

On the contrary, a negative correlation was observed between antidsDNA autoantibodies and the TLR9 mRNA content in cells (Komatsuda et al., 2008). Nevertheless, the difference may be explained by the heterogeneity of studied populations (Lartigue et al., 2009).

On the other hand, TLR4 mRNA expression in SLE patients inversely correlated with corticosteroid doses. The occurrence of profound suppression of $T L R 1,-2,-3,-4,-6$ and 9 in liver sinusoidal 76 
endothelial cells in response to dexamethasone treatment, has been reported previously (Broering etal., 2011). Moreover, TLR9 expression negatively correlated with $\mathrm{C} 3$ levels, which is consistent with a recent study (Ghaly et al., 2013).

It has been stated that muscle biopsies of myositis patients show a significantly increased expression of TLR2, TLR3,TLR4, and TLR9 in the skeletal muscle and infiltrating cells as well as the enhanced expression of many cytokines including type 1 IFNs, suggesting that TLRs are engaged in the milieu of affected muscle and subsequently downstream genes are activated (Kim et al., 2010).

In our study, TLR4 and TLR 9 were upregulated in the muscle tissue of DM group versus that of the control group. Though, their expression showed insignificant difference in PBMCs from subjects of both groups.

These results are in agreement with the results of a former study reporting that the mRNA expression levels of TLR4 were significantly higher in the muscle tissue of the patients group compared to those of the controls (Brunn et al., 2012).

The possible mechanisms of TLR overexpression stems from the contribution of either various microbial pathogens considered as etiologic agents, or the endogenous molecules and cytokines that are generated during muscle damage or immune response. Our study showed that within DM group, TLR4 and TLR9 expressions in muscle tissue were statistically significantly higher $(\mathrm{P}<0.05)$ than that in the PBMCs of the same group and are statistically significantly correlated with the DM Disease Activity Score (DAS) and CK levels. However, only TLR4 expression negatively correlated with corticosteroid doses. Excessive physical activity and strenuous exercise in normal individuals leads to modest elevations in serum muscle enzymes such as creatine kinase (CK), whereas myositis patients generally show a significant increase in $\mathrm{CK}$, suggesting that skeletal muscle leakiness and damage occur in this disease. It is likely that some DAMPs leak from the injured skeletal muscle and engage their receptors on both skeletal muscle and immune cells, thereby perpetuating the inflammatory process (Brunn et al., 2012). 


\section{CONCLUSION}

Our results may suggest a detrimental role of TLR4, TLR9 signaling and innate immune system in the pathogenesis of SLE and DM through activation of TLR pathway. Moreover, the results propose that targeting TLRs and their signaling pathways may lead to development of a new class of efficacious drugs for down-streaming the auto-inflammatory response and control disease activity in both SLE and DM disorders.

\section{REFERENCES:}

Abdollahi-Roodsaz S., Joosten, L.A., Koenders, M.I., Devesa, I., Roelofs, M.F., Radstake, T.R., Heuvelmans-Jacobs, M., Akira, S., Nicklin, M.J., Ribeiro-Dias, F., and van den Berg W.B. (2008): Stimulation of TLR 2 and TLR4 differentially skews the balance of T cells in a mouse model of arthritis. J Clin Invest 118, 205.

Blasiusn, A.L. and Beutler, B. (2010): Intracellular Toll-like receptors. Immunity 32, 305.

Bode, R.K., Klein-Gitelman, M.S., Miller, M.L., Lechman, T.S. and Pachman L.M. (2003): Disease activity score for children with juvenile dermatomyositis: Reliability and validity evidence. Arthritis Rheum 49, 7.

Bombardier, C., Gladman, D.D., Urowitz, M.B., Caron, D., and Chang, C.H., (1992): Derivation of the SLEDAI. A disease activity index for lupus patients. The Committee on Prognosis Studies in SLE. Arthritis Rheum 35:630.

Bøyum, A. (1968): Isolation of mononuclear cells and granulocytes from human blood. Scand. J. Clin Lab Invest 21, 77.

Broering, R., Montag, M., Jiang, M., Lu, M., Sowa, J.-P., Kleinehr, K., Gerken, G., and Schlaak, J. F. (2011): Corticosteroids shift the Tolllike receptor response pattern of primary-isolated murine liver cells from an inflammatory to an anti-inflammatory state. Int Immunol 23, 537.

Brunn, A., Zornbach, K., Hans, V.H., Haupt, W.F., and Deckert, M. (2012): Toll-like receptors promot e inflammation in idiopathic inflammatory myopathies. J Neuropathol Exp Neurol 71, 855.

Christensen, S.R., Shupe, J., Nickerson, K., Kashgarian, M., Flavell, R.A., and Shlomchik, M.J., (2006): Toll like receptor 7\&9 dictate auto antibody specificity \& have opposing inflammatory \& regularity roles in a murine model of lupus. Immunity 25, 417. 
Crampton, S. P., Morawski, P. A. and Bolland, S. (2014): Linking susceptibility genes and pathogenesis mechanisms using mouse models of systemic lupus erythematosus. Disease Models \& Mechanisms 7, 1033.

Davila. E. and Kolls J .A. (2010):“Toll” for Th17 cell expansion. J Leukoc Biol 88, 5.

Denk, S., Perl, M., and Huber-Lang, M. (2012): Damage and pathogen associated molecular pattern and alarmins: keys to sepsis? Eur Surg Res 48, 171.

Dolhain, R.J., van der Heiden A.N., ter Haar, N.T., Breedveld, F.C., Miltenburg, A.M., (1996): Shift toward T lymphocytes with a T helper 1 cytokine-secretion profile in the joints of patients with rheumatoid arthritis. Arthritis Rheum 39, 1961.

Elkon, K.B. and Stone, V.V. (2011): Type I interferon and systemic lupus erythematosus. Journal of Interferon and Cytokine Research 31, 803.

Ghaly, N.R., Kotb, N.A., Nagy, H.M., Rageh, el S.M. (2013): Toll-like receptor 9 in systemic lupus erythematosus, impact on glucocorticoid treatment. J Dermatolog Treat. 24, 411.

Gladman, D.D., Goldsmith, C.H., Urowtiz, M.B., Bacon P., Bombardier, C., Isenberg, D., Kalunian, K., Liang, M.H., Maddison, P. and Nived, O. (1992): Crosscultural validation and reliability of three disease activity indices in SLE .J Rheumatol 19,608.

Husebye, H., Halaas, Ø., Stenmark, H., , Tunheim, G., Sandanger, Ø., Bogen, B., Brech, A., Latz, E., and Espevik T. (2006): Endocytic pathways regulate Toll-like receptor 4 signaling and link innate and adaptive immunity. EMBO J 25,683.

Iwasaki A., and Medzhitov, R. (2010): Regulation of adaptive immunity by the innate immune system. Science 327, 291.

Kim, G.T., Cho, M.L., Park, Y.E., Yoo, W.H. Kim, J.H. Oh, H.J., Kim, D.S., Baek, S.H., Lee, S.H., Lee, J.H., Kim, H.Y. and Kim, S.I. (2010): Expression of TLR2, TLR4, and TLR9 in dermatomyositis and polymyositis. Clin Rheumatol 29, 273.

Klonowska-Szymczyk, A., Wolska, A., Robak, T., Cebula-Obrzut, B., Smolewski, P., and Robak, E. (2014): Expression of Toll-Like Receptors 3, 7, and 9 in Peripheral Blood Mononuclear Cells from Patients with Systemic Lupus Erythematosus. Mediators of Inflammation 2014, Article ID 381418

Komatsuda, A., Wakui, H., Iwamoto, K., Ozawa, A. M., Togashi, M., Masai, R., Maki, N., Hatakeyama, T., and Sawada, K., (2008): Upregulated expression of Toll-like receptors mRNAs in peripheral blood 
mononuclear cells from patients with systemic lupus erythematosus. Clin Exp Immunol 152, 482.

Lartigue, A., Colliou, N., Calbo, S., François, A., Jacquot, S., Arnoult, C., Tron, F., Gilbert, D., and Musette, P., (2009): Critical Role of TLR2 and TLR4 in Autoantibody Production and Glomerulonephritis in lpr Mutation-Induced Mouse Lupus. J Immunol 183, 6207.

Leadbetter, E.A., Rifkin, I.R., Hohlbaum, A.M., Beaudette, B.C., Shlomchik, M.J., and Marshak-Rothstein, A. (2002): Chromatin-IgG complexes activate B cells by dual engagement of IgM and Toll-like receptors. Nature 416, 603.

Lim, K.-H., and Staudt, L. M. (2013): Toll-Like Receptor Signaling. Cold Spring Harb Perspect Biol 5, a011247.

Lin, L., Gerth, A.J., and Peng, S.L. (2004): CpG DNA redirects classswitching towards "Th1-like" Ig isotype production via TLR9 and MyD88. Eur J Immunol 34, 1483.

Liu, B., Yang, Y., Dai, J., Medzhitov, R., Freudenberg, M. A., Zhang, P. L., and Li, Z. (2006): TLR4 Up-Regulation at Protein or Gene Level Is Pathogenic for Lupus-Like autoimmune disease J Immunol 177, 6880.

Livak K.J., and Schmittgen, T.D. (2001): Analysis of relative gene expression data using real-time quantitative PCR and the $2^{\text {(-Delta Delta } C(T))}$ Method. Methods 25, 402.

Ma, K., Li, J., Fang, Y., and Lu, L. (2015): Roles of B cell intrinsic TLR signals in systemic lupus erthymatosus. Int J Mol Sci 9, 13084.

Migita, K., Miyashita, T., Maeda, Y., Nakamura, M., Yatsuhashi, H., Kimura, H., Ishibashi, H., and Eguchi, K. (2007): Toll-like receptor expression in lupus peripheral blood mononuclear cells. J Rheumatol 34, 493.

Mortaz, E., Adcock, I.M., Ito, K., Kraneveld, A.D., Nijkamp, F.P., and Folkerts, G. (2010): Cigarette smoke induces CXCL8 production by human neutrophils via activation of TLR9 receptor. Eur Respir J 36, 1143.

Mu, R., Sun, X. Y., Lim, L. T., Xu, C.H., Dai, C.X., Su, Y., Jia, R. L.a and Li, Z.G. (2012). Toll-like receptor 9 is correlated to disease activity in Chinese systemic lupus erythematosus population, Chin Med J (Engl) 125, 2873.

Pradhan, V.D., Das, S., Surve, P. and Ghosh, K. (2012): Toll-like receptors in autoimmunity with special reference to systemic lupus erythematosus. Indian J Hum Genet 18, 155.

Rönnblom, L. and Eloranta, M.L. (2013): The interferon signature in autoimmune diseases," Current Opinion in Rheumatology. 25, 248. 
Salway, F., Day, P.J.R., Ollier, W.E.R., Peakman, T.C. (2008): Levels of 5' RNA tags in plasma and buffy coat from EDTA blood increase with time. International Journal of Epidemiology 37, i11.

Szebeni, B., Veres, G., Dezsõfi, A., Rusai, K., Vannay, Á., Mraz, M., Majorova, E., and Arato, A. (2008): Increased expression of Toll-like receptor (TLR) 2 and TLR4 in the colonic mucosa of children with inflammatory bowel disease. Clinical and Experimental Immunology 151, 34.

Tsokos, G.C. (2011): Mechanisms of disease: systemic lupus erythematosus. New England Journal of Medicine 365, 2110.

Wiame, I., Remy, S., Swennen, R., and Sagi, L. (2000): Irreversible heat inactivation of DNaseI without RNA degradation. Biotechniques 29, 252.

Wong, C. K., Wong, P. T. Y., Tam, L. S., Li, E. K., Chen, D. P. and Lam, C.W. K. (2010): Activation profile of Toll-like receptors of peripheral blood lymphocytes in patients with systemic lupus erythematosus. Clinical and Experimental Immunology 159, 11.

Yasuda, K., Richez, C., Uccellini, M.B., Richards, R.J., Bonegio, R. G., Akira, S., Monestier, M., Corley, R.B., Viglianti, G. A., MarshakRothstein, A., and Rifkin, I.R. (2009): Requirement for DNA CpG content in TLR9-dependent dendritic cell activation induced by DNAcontaining immune complexes. J Immunol 183, 3109. 